\title{
Control Method of Slipstream Gas Source System of a Propeller
}

\author{
Jinchun Shi \\ China Aviation Planning and Design Research Institute Co., Ltd.
}

\begin{abstract}
For the slipstream gas source control system of propeller, there is no mature application in China. The traditional slipstream gas source system manually realizes the stable control of gas and flow through the self-operated pressure reducing device. But this mode can only be used in the condition of small pressure and low flow, cannot meet the actual need of high pressure and large flow, and cannot monitor and automatically control the energy consumption of compressed gas and heating equipment, resulting in great energy waste. Based on the actual engineering conditions, and according to the characteristics, user requirements and work flow of the slipstream gas source system, this paper describes a new control method for the slipstream gas source system of a propeller in detail, which solves the issue of automatic control in the whole process and realizes the key technical point, rapid stabilizing of airflow pressure and temperature.
\end{abstract}

Keywords: Slipstream gas source; Pressure temperature; Control method.

\section{Introduction}

The propeller-driven aircraft uses the rotation of the propeller to convert the power of the engine into a pulling force to move forward. The influence of the propeller on the aircraft mainly includes direct influence and indirect influence. The direct influence is mainly the tensile force, torque and normal force it generates, and the tensile force and torque can be obtained by theoretical calculation. However, in most cases, it is very difficult to obtain the data of normal force of the propeller changing with the drift angle of the airflow. Although there are empirical formulas that can estimate the impact, estimation is far from enough. At present, the effective way to solve this problem is still the ground test. The development of the slipstream test system provides experimental equipment and technical support for the propeller slipstream test.

\section{Operation principle of slipstream gas source system}

The ground propeller slipstream gas source test system is used to provides table temperature, pressure and flow gas source for the ground propeller. The propeller gets different speeds by changing the inlet air volume of the propeller, and this ground simulation test analyzes the parameters including the speed and force of the propeller collected through the data acquisition system. This paper only describes the slipstream gas source system, not involving the propeller data acquisition and analysis system.

\subsection{Composition of propeller slipstream gas source system}

The schematic diagram of the propeller slipstream gas source system is shown in Figure 1-1.

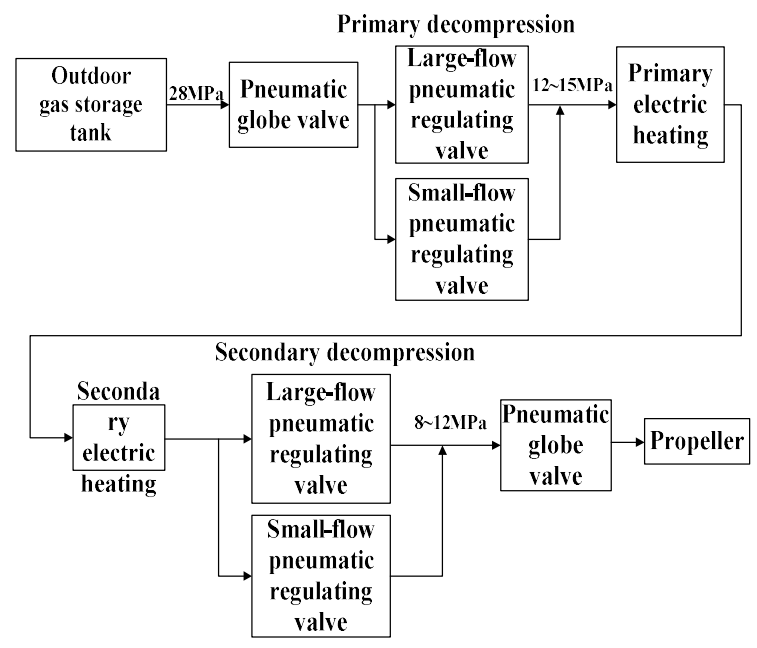

Figure 1-1. Schematic Diagram of the Propeller Slipstream Gas Source System. 
The slipstream gas source system mainly comprises outdoor gas storage tank, heat-preservation high-pressure pipeline, pneumatic globe valve, primary/secondary large/small flow pneumatic pressure regulating valve, primary/secondary electric heating, temperature, pressure sensor and control system. The control system is mainly composed of upper monitor, PLC controller, UPS, switchboard and other equipment, using for remote monitoring and automatic control of the slipstream gas source system.

\subsection{Operation principle of propeller slipstream gas source system}

The outdoor gas tank can store high-pressure gas up to $28 \mathrm{MPa}$, dropping to $12 \sim 15 \mathrm{MPa}$ after passing through primary large/small flow pressure reducing valve, and to $8 \sim 12 \mathrm{MPa}$ after passing through large/small flow pressure reducing valve. The high-pressure airflow blows the propeller to rotate, and then data collection and analysis are carried out.

As is shown in Figure 1-1, the primary and secondary decompression of the propeller slipstream gas source system are composed of two pneumatic pressure regulating valves in parallel. The two pressure regulating valves work in coordination to ensure that the pressure and flow at the outlet can meet the requirements. While the gas flow rate is in the small flow range, the small pressure reducing valve participates in the control, and while the gas flow rate is in the large flow range, large and small pressure reducing valves work in combination. After the primary decompression, pressure sensor is set on the main pipeline as the control target of primary decompression system, and the pressure sensor is set after the secondary decompression as the pressure control target of end propeller.

\subsection{Characteristics and key control points of slipstream gas source system}

The control objects of propeller slipstream gas source system are temperature, pressure and flow. The control variables include primary large and small pressure reducing valves and secondary large and small pressure reducing valves. The system is characterized by many control variables and coupling control objects. At the same time, in the large-flow experiment mode of the propeller, the experiment lasts only a few minutes, while the gas charging of gas tank consumes several hours each time. If the terminal stable gas flow cannot be established quickly, it will directly affect the normal test and cause manpower and economic cost waste.

\section{Control methods of slipstream gas source system}

The control parameters of the propeller slipstream gas source system are pressure, flow and temperature. After debugging, it is found that there is a certain relationship between pressure and flow. According to the debugging curve, the pressure-flow corresponding function relationship can be derived. Meanwhile, the high-pressure air exchanges heat through the water-gas heat exchanger. Due to the large amount of circulating water, it is difficult to affect the temperature of the circulating water system since the air temperature falls during the depressurization process. The water in the water tank is heated to the preheat temperature by the electric heater before the test, and it is relatively easy to achieve temperature control by adjusting the three-way proportional valve of cold and hot water in the test. In the operation of the system, it is found that the coupling between temperature and pressure is not obvious, so that the key of the system lies in the control of high-pressure airflow pressure. This paper mainly describes the control methods of slipstream gas source pressure.

\subsection{Control of slipstream airflow pressure}

According to the characteristics of the system, the separate control idea of primary and secondary decompression is adopted. Primary decompression is divided into pressure maintaining mode and pressure stabilizing mode, and secondary decompression is divided into large-flow mode and small-flow mode. Primary decompression is first controlled and then primary decompression and secondary decompression are controlled jointly after the pressure reaches the set value of pressure maintaining, and finally reaches the set pressure value of the propeller front end. The control flow of airflow pressure is shown in Figure 2-1.

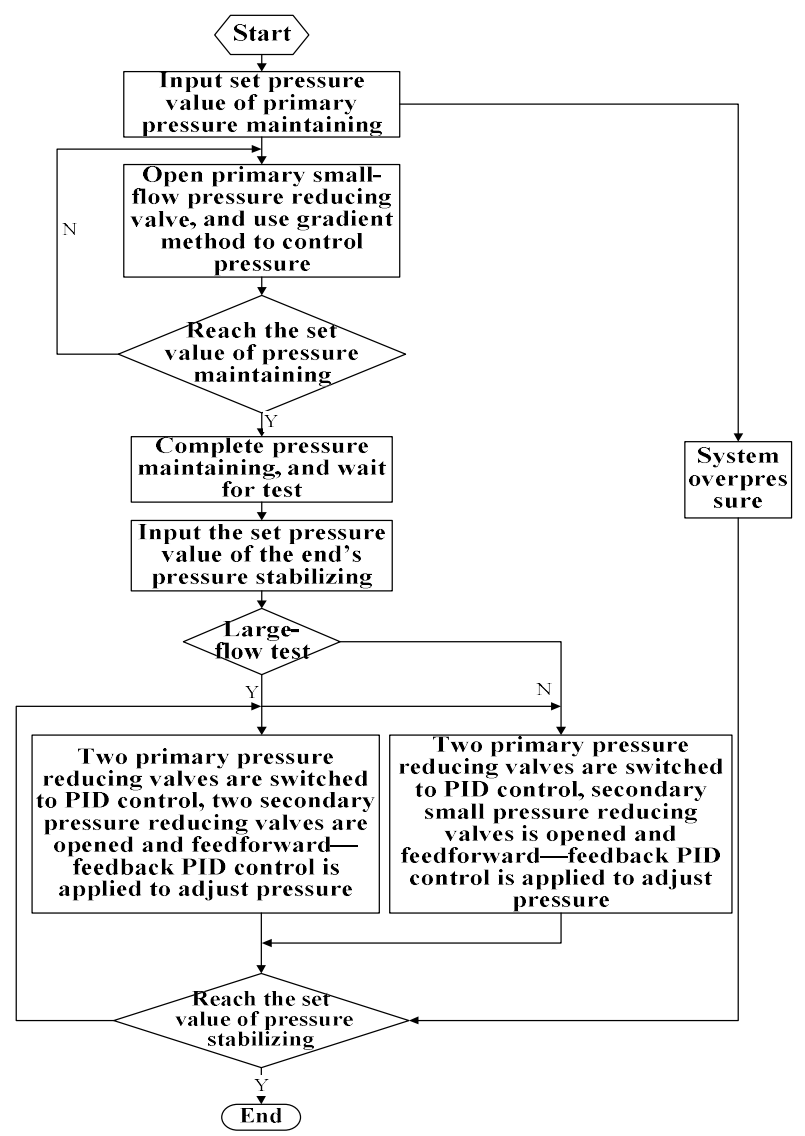

Figure 2-1. Flow Chart of Slipstream Gas Source Pressure Control. 
First, set the pressure value of pressure maintaining after the primary decompression. Since the requirement for time and process is not high in this process, primary small-flow pressure reducing valve can meet the requirement. The gradient pressure control method is adopted specifically, that is to compare the difference between the set value and the feedback value. When the difference is large, the opening command is directly sent to the small pressure reducing valve, then the difference is compared in real time, and the opening of the small pressure reducing valve is continuously reduced until the pressure is stable. If the set value monitored is $2 \mathrm{MPa}$ larger than the feedback value, the primary small pressure reducing valve is directly opened to $50 \%$, and when the set value is $1 \mathrm{Mpa}$ larger than the feedback value, the primary small pressure reducing valve is directly opened to $20 \%$.As the gas in the outdoor high-pressure gas tank continuously enters the pipeline, the difference between the set value and the feedback value is continuously reduced, and the opening of the primary small pressure reducing valve is also continuously decreased until the difference between the set value and the feedback value is 0 .

Secondly, after the pressure is maintained, select the large flow or small flow mode according to the requirements of propeller test and input the set pressure value of secondary end pressure stabilizing. When the large flow mode is selected, the two primary pressure reducing valves are switched to PID control mode, and the control object is the pressure before secondary ecompression. And the two secondary pressure reducing valves are switched to feedforward-feedback PID control mode. In the small flow mode, the two primary pressure reducing valves are also switched to PID control mode, the secondary large pressure reducing valve is closed, and the small pressure reducing valve adopts feedforward-feedback PID control.

\subsection{Feedforward-feedback PID control of pressure}

The opening value of secondary decompression valve is the superposition value of the feedforward and feedback output. The feedforward plays the role of fast preset, while the feedback plays a fine adjustment function. Since there is no feedforward-feedback control switching, the pressure fluctuation caused by the switching can be prevented. Due to the existence of the feedforward algorithm, the anti-interference of the system is greatly improved.

The principle of feedforward-feedback PID control is shown in Figure 2-2.

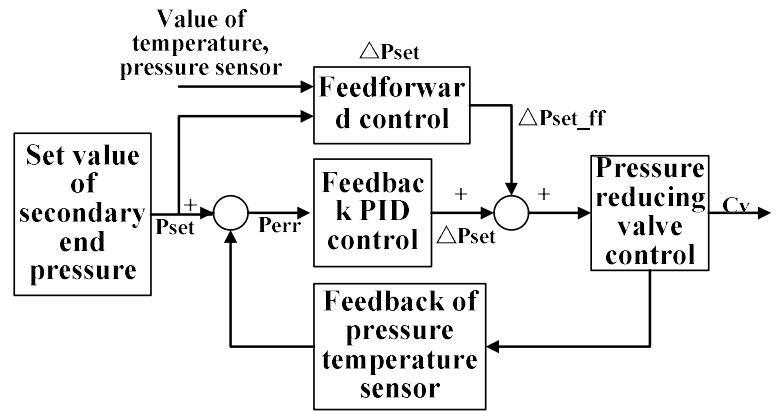

Figure 2-2. Schematic Diagram of Primary Pressure Feedforward-feedback PID Control of Slipstream Gas Source.

1. The formula for calculating the $\mathrm{Cv}$ value of valve opening is shown as follows:

$$
C_{V}=k 1.167 \cdot Q_{V} \sqrt{\frac{\rho \cdot \Delta P_{0}}{\rho_{0} \cdot \Delta P}}
$$

In the formula: $\mathrm{CV}$ - valve opening

$\mathrm{k}$-flow coefficient

$\mathrm{Qv}$ - gas volume flow, $\mathrm{m}^{3} / \mathrm{h}$;

$\rho$ - gas density of high-pressure air, $\mathrm{kg} / \mathrm{m}^{3}$;

$\rho 0$ - the density of water, $1000 \mathrm{~kg} / \mathrm{m}^{3}$;

$\triangle \mathrm{P}$ - pressure difference between the valve front and valve back, Mpa;

$\triangle \mathrm{P} 0-0.1 \mathrm{Mpa}$;

2. Calculation formula of compressed air volume flow:

$$
Q_{V}=\frac{3600 \cdot Q_{m}}{\rho}
$$

In the formula: $\mathrm{Qv}$ - gas volume flow, $\mathrm{m}^{3} / \mathrm{h}$;

Qm-gas mass flow, kg/s;

$\rho$ - gas density of high-pressure air, $\mathrm{kg} / \mathrm{m}^{3}$;

3. Calculation formula of compressed air density:

$$
\rho=\frac{P}{R \cdot T}
$$

In the formula: $\rho$-gas density of high-pressure air, $\mathrm{kg} / \mathrm{m}^{3}$;

$\mathrm{P}$ - gas pressure of the valve front, $\mathrm{Pa}$;

$\mathrm{T}$ - gas temperature of the valve front, $\mathrm{K}$;

$\mathrm{R}$-gas constant, $287 \mathrm{~J} /(\mathrm{kg} * \mathrm{~K})$;

The feedforward value of valve opening is calculated as follows:

1. First calculate the gas density at the valve by formula (3);

2. Calculate the volume flow rate $\mathrm{Qv}$ by formula (2);

3. Calculate the valve opening $\mathrm{Cv}$ by formula (1).

The pressure values are the value measured by the sensor and the input set value of the upper computer, and the temperature value is the measured value of the sensor. The calculated valve opening is superimposed with the PID output algebra and then sent to the secondary pressure reducing valve locator through the PLC analog output module. The valve can be directly opened to a predetermined opening degree and then precisely adjusted to achieve rapid pressure stabilizing control. The coefficientk of $\mathrm{Cv}$ value obtained through the repeated debugging of the system is 1.05 . 
The secondary pressure reducing curve recorded in the test is shown in Figure 2-3.

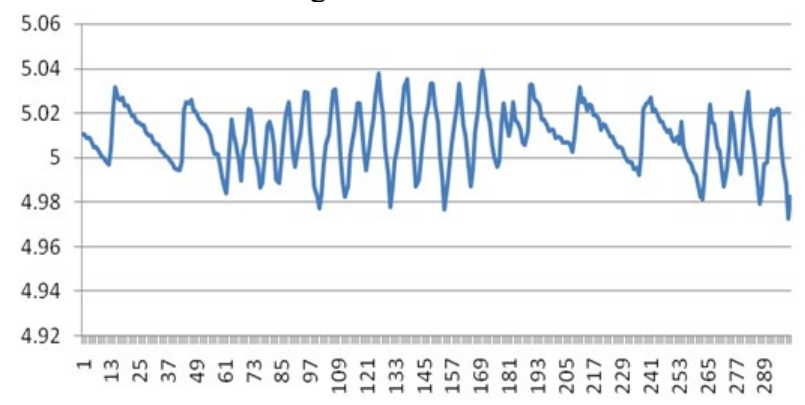

Figure 2-3. Secondary Decompression Pressure Curve of Slipstream Gas Source.

The above figure shows the pressure curve of ground propeller test, the abscissa is the acquisition time, the ordinate is the pressure of propeller end, the sampling rate is $1 \mathrm{time} / \mathrm{s}$, and the pressure value of propeller inlet is set to $5 \mathrm{Mpa}$. It can be seen from the above figure that the end pressure is stabilized between $4.98 \sim 5.04 \mathrm{Mpa}$, that is, $\pm 0.03 \mathrm{Mpa}$, which meets the technical specifications. Meanwhile, the set values of other different pressures also meet the requirement of technical parameters.

\section{Conclusion}

The control system and control method designed in this paper can monitor the control and status of gas pressure, temperature and flow of the ground propeller slipstream gas source in real time, and quickly achieve the stable high-pressure gas pressure and temperature required by the propeller, which is an automated control technology for testing propellers applied in the ground.

According to the test process and system characteristics, through applying gradient pressure control on primary and secondary decompression, the combination of classic PID control and feedforward-feedback PID control, the rapid and stable control on the pressure and flow of propeller slipstream gas source is achieved, meeting the test requirements.

The system has been applied for a year and a half with good operation. Compared with the traditional gas source control, the flexibility and stability are greatly improved. It provides a variety of combination modes for the propeller ground test, seamlessly connects the propeller data acquisition system and fills the blank in the field of domestic ground propeller automatic control. 